\title{
The analysis of the situations of hot spring tourism in Yunnan
}

\author{
Wen Gao \\ Oxbridge college, Kunming university of science and technology,panpanbear@hotmail.com
}

\begin{abstract}
Key words: hot spring tourism Yunnan province
\end{abstract}
\begin{abstract}
The preliminary census identified that Yunnan abounds with out the 1266 natural hot springs and water covered, accounting for about one-third of total of hot springs, and the ranking the first among the provinces and regions in China. In nearly few years, Yunnan's tourism industry association suggested that the whole industry face to Transco formation and upgrading. The development of hot spring be considered another motive power for this strategy.

Yunnan province is located in the southwest of China, but it nickname "kingdom of plants", "animal kingdom" and "geothermal state" . In recent years, with the increase of per capita disposable income in our country, travelers require the depth of the tourism and new route plans. the extensive mode of tourism in Yunnan traditional face to transformation and upgrading. This article will points out the advantages of Yunnan hot spring tourism, the situations of its development. Finally, the article seem to give some suggestion of how to develop the hot spring tourism in Yunnan .
\end{abstract}

\section{Yunnan has plenty recourses of hot spring tourism}

Yunnan seem to using the hot spring tourism to accelerate the speed of Transco formation and upgrading. It based on three absolute advantages.

Yunnan has huge number of hot spring. According to the National Association of SPA statement Yunnan abounds with out the 1266 natural hot springs and water covered, accounting for about one-third of total of hot springs, and the ranking the first among the provinces and regions in China. At the same time, the annual outflow of about 360 million cubic meters of water, the release of heat equivalent to 118.7 tons of standard coal, ranking the second of the China1.

A variety of hot springs and asymmetric distribution. Nearly, Most of the province's cities and regions have hot springs. According to the classification of the chemical composition of the hot spring, Yunnan hot springs can be divided into: bicarbonate, carbonated spring and sulfur springs, which is the main type of bicarbonate of soda, followed by carbonated springs and sulfur springs. According to the classification of hot spring water temperature, the Yunnan hot spring can be divided into four types: low hot springs $\left(25^{\circ} \mathrm{C} \sim 40^{\circ} \mathrm{C}\right)$, medium hot springs $\left(40{ }^{\circ} \mathrm{C} \sim 60{ }^{\circ} \mathrm{C}\right.$ )、 high hot springs ( $\left(60^{\circ} \mathrm{C} \sim 80^{\circ} \mathrm{C}\right)$ ), and over heated springs (above $96^{\circ} \mathrm{C}$ ). Medium and high hot springs are main part. If according to the production, Yunnan hot spring can be divided into: natural and artificial hot spring spa.

The others characterize of Yunnan hot spring tourism is asymmetric distribution. Western of Yunnan hot spring recourses account of about two-third, the eastern just has one-third. In the area distribution of hot springs with high hot springs, represented by Tengchong, the geothermal temperature high, the pressure of steam. The middle of Yunnan and the eastern of Yunnan take the low hot spring. In this area, there are some famous hot spring zone, such as An'ning and Bolian

1 Xinyang Liao, the country of hot spring, Yunnan daily, Nov, 2013. 
resort and SPA.

Most hot springs have medical utility. Hot springs are rich in minerals, playa role in the treatment of various diseases. in addition to the hot springs also has beauty, health, skin care functions. variety of methods of bathing, drinking, etc. It can be inhaled, keeping fitness, illnesses and beauty. The hot springs in Yunnan are dominated by bicarbonate of soda. Then mainly from the following spring quality to illustrate the medical effect of hot springs.

Carbonated water is known as the heart of spring in Europe, because of its expansion of peripheral blood vessels, reduce blood pressure, improve blood flow The application of carbonated spring is mainly hypertension, heart disease patients, but also for the treatment of menopausal syndrome, chronic rheumatoid arthritis, etc. In addition, the release of carbon dioxide gas springs can improve the skin feeling effect and inhibit sensation on the temperature. Yunnan has typical carbonated spring in Dianchi springs, Mile Huquan hot springs and hot spring area in Trenching.

Sulphur Springs are superior to carbon dioxide in the expansion of peripheral blood vessels, so they can be used to treat arteriosclerosis, hypertension and heart disease. Sulfur springs can also be used to save metal poisoning and drug poisoning and chronic eczema treatment. Hydrogen sulfide and expectorant effect, can alleviate chronic bronchitis, bronchiectasis and other diseases, it is also known as the spring phlegm. But more than above a certain concentration of hydrogen sulfide is toxic, the bath must pay attention to ventilation. In addition to the usual bath treatment, but also to carry out a special fumigation therapy. Direct fumigation of human body by underground heat steam to achieve the purpose of treatment. Such as in Tengchong and Dali spring areas.

(a) Simple spring is various components have little effect but the content, also the most complete, to skin disease, scar repair, fracture to rheumatism, gastritis, diuretic As Huaning hot spring. The correctly use of the hot spring bath can promote health condition. Wellness Spa function will be the main reason why people come to the hot spring tourism. The hot spring enterprise should find out the hot spring water quality, accurately mark the beneficial ingredient content, list the curative effect and provide the professional medical personnel, which is an important factor to increase the attraction and competitiveness.

\section{The situations of the Yunnan hot spring tourism}

Yunnan has some strengths in developing hot spring tourism, but also we should not avoid some problems in developing processes.

i. The development of Yunnan hot spring tourism is in different stage. As early as,2008 Chinese international tourism fair, Yunnan Tourism Industry Association suggest put forward the construction of Yunnan province's vision of spring. According to the Yunnan Tourism Association SPA statistics there are 16 cities in Yunnan province has existing hot spring resources.Afew cities came to maturity. For example, in Tengchong city, there are two famous hot spring zone, namely“Huo Shang Re Hai” and Angsana Tengchong Hot Spring. But a plenty number cities still in the initial stage. There are no planning, no equipments and no investments. These hot spring are virgins. Overall, the proportion of Yunnan health spa tourism product is too narrow, generally did not make full use of medical utility spa better to maximize its economic and social benefit.The industry chose the developingmode is that most important is recourses, then is planning, and finally, it will come to management. According to the statistics of the Yunnan Provincial Tourism Association SPA2.In 2016, there are 1085 enterprises and self-employed households working in hot spring tourism.The hot spring industry createout value of 24 billion 380 million Yuan, and the

2Ning Fu, Spa in Yunnan, Yunnan peoplepublish, 2016. 
consumers of hot spring tourists more than 6 million 724 thousand passengers of which the provincecustomersaccounted for $51.8 \%$, foreign tourists accounted for $45.7 \%$, accounting for $2.5 \%$ contributed by overseas tourists.During these enterprises, there are 757 self-employed households, account for68.8\%. Only 8.2\% is high standard hotels that content resort and spa services. Based on the data. The industry of hot spring tourism seem that lack of top-level design, multi rules, the integration of various departments of the policy and planning and the degree of industrialization should be improved.

ii.The leader of the industry gathered in Yunnan. In December 22, 2013, the first Chinese spa Jintang award issued 78 awards, enterprises and individuals to encourage and reward outstanding performance and contribution in the spring industry. This award represents the highest level of China's hot springs tourism, and to promote and plan the sustainable development of China's hot spring tourism industry.78 Awards (20 categories), Yunnan included 8 awards. These excellent Jintang spa brand represents the top of Yunnan hot springsindustry, push the Yunnan hot spring development. But it just account for few part.

iii. only tow exploremodes of Yunnan hot spring tourism

one mode is combination for sightseeing, health care and hot spring resources. This type is represented by Anning hot spring and Bolian spa.In this type, the productions are mainly service for the city tourists, and content leisure, the top meeting, business, beauty and body function.Usually this mode has a multi-functional gymnasium, beauty equipment, large business hall, hot spring resort hotel, a golf course. And combined with the surrounding natural environment into create a local characteristics of the open-air bath style.

Another mode isputtingnational culture and hot spring resources together. Thismode of hot spring tourism is concentrated in the areas of ethnic minorities. This type of hot spring resource development based on spring resources and unique national culture of bath, and mixed national diet, national costume show, various ethnic festivals and unique ethnic customs into productions to attract tourists visiting. Such as Ninlang's Yongning hot spa zone that located in Lugu lake.

\section{Suggestions}

According above analysis about the problems in Yunnan hot spring tourism. There are several suggestionsshould be mention.

i Try to change the polarization phenomenon. The government should make a strategy for the hot spring tourism.published Quantitative industry requirements when self-employed households came into market. Improving the operating environment, let the experience of leisure travel easily, and get higher medical effect.

ii. Add hot spring tourism development mode

Hot springs in Yunnan are variety, and also havesome a medical effect. according to different hot springs health utility to depth development of hot springs, and establish medical hot spring area. Such as Baoshan Baihua mountain hot springs have good curative effect on rheumatism and skin disease.

In addition to ethnic minorities in Yunnan, other characteristic is geological features, such as karts' landform. It can be make karts' landform and hot spring put together in this region.

iii. The hot spring recourses is limited. The transformation and upgrading is long-term plan. How to make the impetus durable and forceful, the method of sustainable development should be considered.

All in all, developing hot spring tourism in Yunnan is an outstanding strategy for the whole industry. This plan also be induced in Yunnan "Shisiwu". 


\section{Reference:}

[1].Ning Fu, Spa in Yunnan, Yunnan peoplepublish, 2016.

[2].XinYang Liao, the country of hot spring, Yunnan daily, Nov, 2013.

[3].Gangqian Yu, the usage of Yunnan tourismresources. Ecological economy,2000

Hot spring, Yunnan peoplepublish, 1999.

[4].The planning of the tourism development in Tengchong, 2003, Yunnan normal university.

[5].Wei Feng, The research of the tend in tourism development. Yunnan economicuniversity, May, 2003.

[6]Ming Zhao, The pearl of hot spring tourism in Shuifu, Ecological economy. May 2005.

[7].Qian wu, the strategy of the development in Yunnan, Ecological economy. Dec 2012. 